(1)

\title{
Gastric Outlet Obstruction Palliation: A Novel Stent-Based Solution
}

\author{
Natasha M. Rueth Rafael S. Andrade Shawn S. Groth \\ Michael A. Maddaus Jonathan D'Cunha \\ Division of Thoracic and Foregut Surgery, Department of Surgery, University of \\ Minnesota, Minneapolis, Minn., USA
}

\section{Key Words}

Endoscopy · Stents · Gastric outlet obstruction · Palliative care

\begin{abstract}
Gastric outlet obstruction (GOO) after esophagectomy is a morbid outcome and significantly hinders quality of life for end-stage esophageal cancer patients. In the pre-stent era, palliation consisted of chemotherapy, radiation, tumor ablation, or stricture dilation. In the current era, palliative stenting has emerged as an additional tool; however, migration and tumor ingrowth are ongoing challenges. To mitigate these challenges, we developed a novel, hybrid, stent-based approach for the palliative management of GOO. We present a patient with esophageal cancer diagnosed with recurrent, metastatic disease 1 year after esophagectomy. She developed dehydration and intractable emesis, which significantly interfered with her quality of life. For palliation, we dilated the stenosis and proceeded with our stent-based solution. Using a combined endoscopic and fluoroscopic approach, we placed a 12-mm silicone salivary bypass tube across the pylorus, where it kinked slightly because of local tumor biology. To bridge this defect and ensure luminal patency, we placed a nitinol tracheobronchial stent through the silicone stent. Clinically, the patient had immediate relief from her pre-operative symptoms and was discharged home on a liquid diet. In conclusion, GOO and malignant dysphagia after esophagectomy are significant challenges for patients with end-stage disease. Palliative stenting is a viable option, but migration and tumor ingrowth are common complications. The hybrid approach presented here provides a unique solution to these potential pitfalls. The flared silicone tube minimized the chance of migration and impaired tumor ingrowth. The nitinol stent aided with patency and overcame the challenges of the soft tube. This novel strategy achieved palliation, describing another endoscopic option in the treatment of malignant GOO.
\end{abstract}




\section{Introduction}

Gastric outlet obstruction (GOO) following esophagectomy is a morbid outcome, particularly for patients with recurrent, end-stage disease. Severe obstruction may lead to aspiration, feeding intolerance, and dehydration $[1,2]$. The overall effect has a profound, negative impact on quality of life. With the rising incidence of esophageal cancer, it is ever important to develop novel, minimally invasive techniques to palliate patients with GOO in the setting of non-operable malignancy. The primary goal should be relief of obstructive symptoms, leading to significant improvements in quality of life for patients with end-stage disease that are unable to tolerate oral intake.

Palliative esophageal or pyloric stenting is a logical solution. Prior to recent advances in stenting, management of malignant dysphagia consisted of systemic chemotherapy, radiation therapy, tumor ablation, or stricture dilation [3], each with its own challenges. With increasing applications for self-expanding stents in the upper gastrointestinal tract, however, palliative stent-based therapy has become a valuable management tool for select patients. In the current report, we present a unique hybrid stent approach for the management of significant GOO following esophagectomy in a patient with end-stage, metastatic esophageal cancer.

\section{Case Report}

Our patient was a 57-year-old female with esophageal cancer. She had an Ivor-Lewis esophagectomy (with pyloroplasty) 1 year previously, but was recently diagnosed with recurrent, metastatic disease. She presented with dehydration and intractable emesis, suggestive of GOO, and required total parental nutrition support. Initial computerized tomography confirmed metastatic disease. Endoscopic evaluation demonstrated a widely patent esophagogastric anastomosis, but with significant pyloric narrowing (maximal circumference $6 \mathrm{~mm}$ ). With the primary aim of short-term palliation guiding our decision-making, we dilated the stenosis to $12 \mathrm{~mm}$ and proceeded with our novel stent-based solution.

We began by placing a 12-mm silicone salivary bypass tube (SBT) (Kapitex Healthcare Ltd, Wetherby, West Yorkshire, England) across the freshly dilated pylorus using fluoroscopic guidance (fig. 1). After successful positioning, we injected contrast to assess patency. Not unexpectedly, the tube had a small kink at the level of the pylorus due to the local effect of the tight stenosis on the soft, silicone SBT. To bridge this, we fluoroscopically guided a $13 \times 6 \mathrm{~mm}$, uncovered, nitinol tracheobronchial stent (Ultraflex ${ }^{\circledR}$, Boston Scientific, Natick, Mass., USA) through the SBT (ig. 2). Post-deployment contrast study showed resolution of the kink, with duodenal contrast distal to the stented area.

Clinically, the patient had immediate relief from her pre-operative symptoms. Routine radiographic evaluation on post-operative day 1 demonstrated excellent stent patency and position (fig. 3 ). Tolerating a full liquid diet without evidence of GOO, she was discharged home without complications. Unfortunately, she died of her metastatic disease 2 weeks later, but remained appreciative of her improved quality of life as she was able to take liquids by mouth during this time.

\section{Discussion}

The incidence of GOO after esophagectomy approaches $10 \%$, even in the setting of pyloric opening procedures $[4,5]$. In a 2002 meta-analysis of nine randomized controlled trials involving over 500 patients, Urschel et al. found that pyloric opening procedures significantly reduced the incidence of early GOO after esophagectomy $(\mathrm{p}=0.046)$ when compared to patients without pyloric drainage [6]. For delayed GOO, however, the results were non-significant, highlighting the importance of effective intervention strategies for patients who develop symptoms of dysphagia remote from their oncologic resection. 
A number of minimally invasive treatment approaches to manage post-esophagectomy GOO have been described, including pyloric botulinum toxin injection [5], balloon dilation [4], and trans-pyloric stenting [7, 8]. Management should be tailored to the patient's functional status, pathology, and timing from original surgery. Early dysfunction, more likely benign, may respond to pyloric injection or dilation. Late outlet obstruction, however, is likely malignant [8] and may require innovative approaches to gain patency. Decision-making can be particularly challenging for these patients due to their grave prognosis. Not surprisingly the mean survival time for patients undergoing palliation of non-operable malignancies is measured in months, at best $[9,10]$. For our patient, metastatic disease, malignant ascites, and malnutrition made her a poor candidate for aggressive surgical intervention; however, the ability to drink was a strong desire for her. Knowing that her life expectancy was short, stent placement afforded the best palliative option.

Palliative upper gastrointestinal stenting has a reported initial success rate of $67-100 \%$ $[2,11,12]$; however, conventional approaches using commercially available stents still carry significant complication rates, most notably stent migration [7] and tumor ingrowth [11]. Despite these potential limitations, the current consensus among many thoracic oncologic surgeons is that stents are a superior approach for achieving relief of dysphagia when compared to other palliative modalities [13].

As a result of our growing series of esophageal stent patients, we have developed a standardized approach to manage and even circumvent the ongoing challenges of stent migration and tumor ingrowth. Our current solution is an aggressive surveillance strategy, with endoscopic evaluation every 2-4 weeks, looking for potential stent migration, erosion, or occlusion. Stents are repositioned or replaced as needed.

Additionally, the hybrid approach presented here provides unique solutions to these potential pitfalls. The flare on the SBT minimizes the chance of migration while the silicone nature of the SBT prevents tumor ingrowth. Collectively, these are paramount considerations when given the underlying condition of end-stage disease. Using this novel strategy, we have demonstrated a minimally invasive way to achieve palliation and importantly, described another endoscopic option in the treatment of malignant GOO. 


\begin{tabular}{r|l|l|l}
$\begin{array}{r}\text { Case Reports in } \\
\text { Gastroenterology }\end{array}$ & $\begin{array}{l}\text { Case Rep Gastroenterol 2010;4:185-190 } \\
\text { D0I: 10.1159/000315560 }\end{array}$ & Published online: June 11, 2010 & $\begin{array}{l}\text { @ 2010 S. Karger AG, Basel } \\
\text { ISSN 1662-0631 } \\
\text { www.karger.com/crg }\end{array}$ \\
\hline
\end{tabular}

Fig. 1. SBT delivery device. 12-mm SBT threaded over the contrast-filled balloon (yellow arrow), ready for trans-pyloric placement. The white arrow points to the suture placed for grasping and endoscopic manipulation after placement.

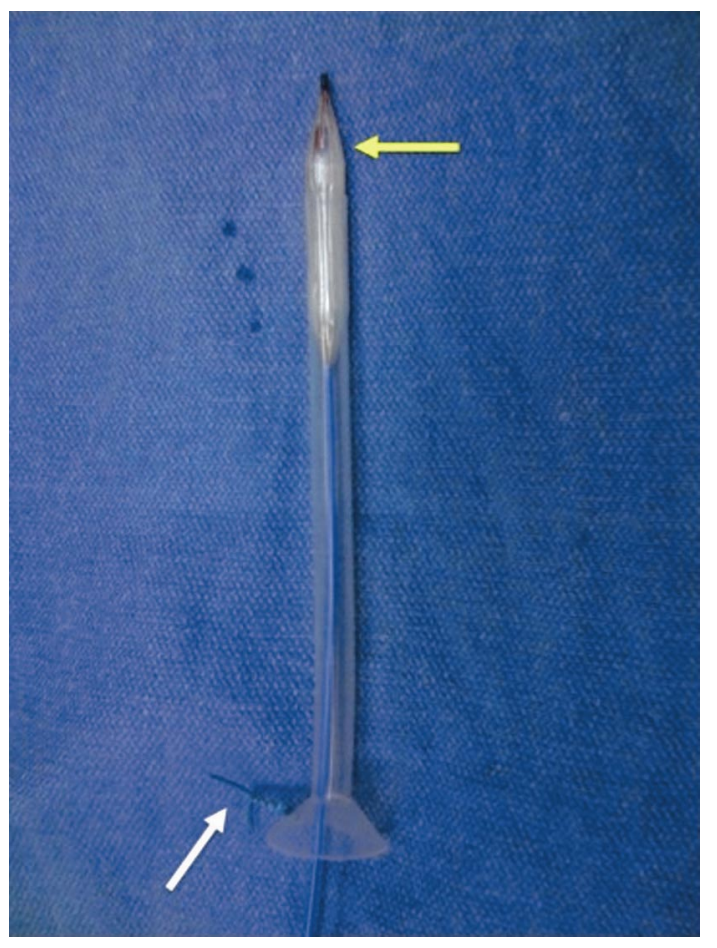

Fig. 2. a Final fluoroscopic image of trans-pyloric stents. The nitinol stent can be seen within the lumen of the SBT. The kink has resolved, demonstrating the success of the hybrid stent procedure. $\mathbf{b}$ Final endoscopic view of trans-pyloric stents. The nitinol stent is completely covered by the silicone SBT. This placement technique mitigates the risk of tumor ingrowth seen when nitinol stents are placed alone.

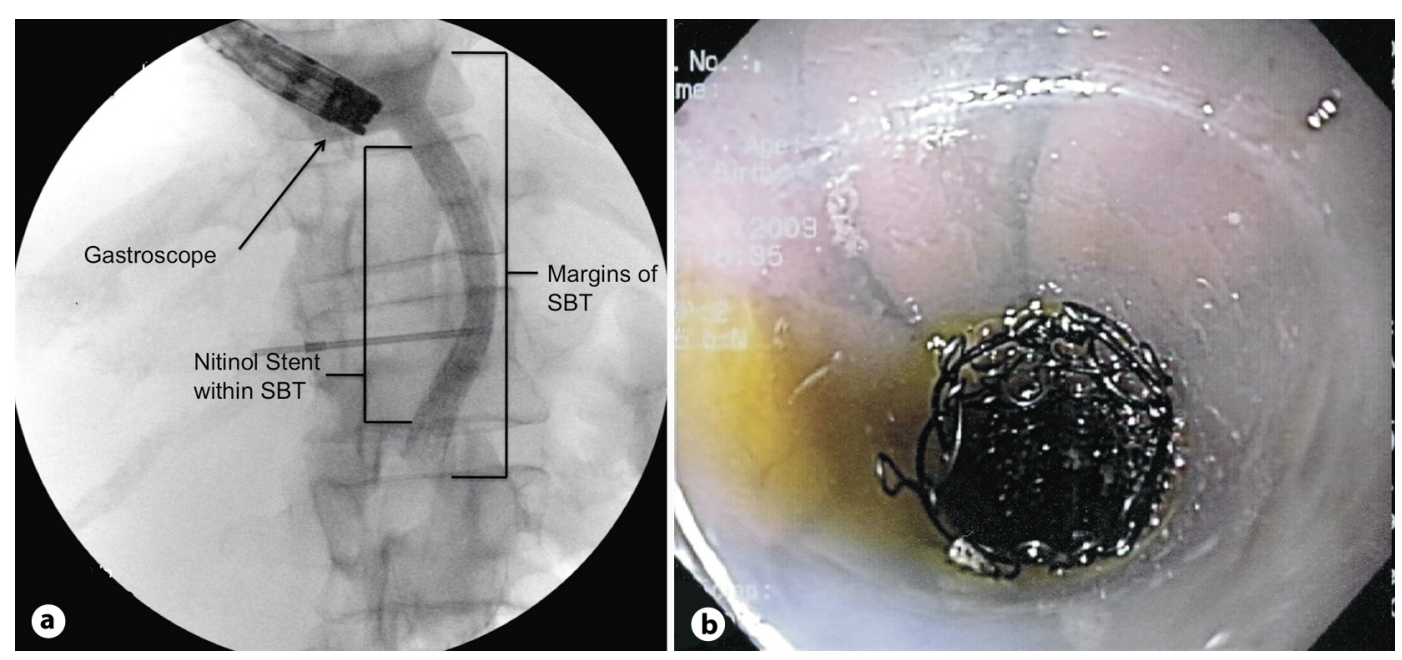


Fig. 3. Post-operative contrast study. Radiographic image showing patency and position of the stents, with contrast flow into the duodenum (arrow). The image demonstrates successful resolution of outlet obstruction.

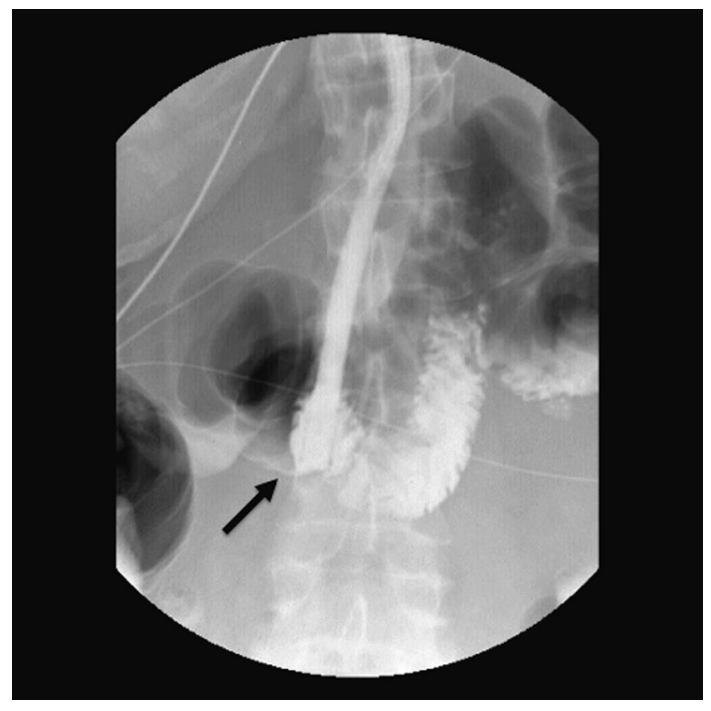




\section{References}

-1 Jeurnink SM, Steyerberg EW, Hof G, van Eijck CH, Kuipers EJ, Siersema PD: Gastrojejunostomy versus stent placement in patients with malignant gastric outlet obstruction: a comparison in 95 patients. J Surg Oncol 2007;96:389-396.

2 Larssen L, Medhus AW, Hauge T: Treatment of malignant gastric outlet obstruction with stents: an evaluation of the reported variables for clinical outcome. BMC Gastroenterol 2009;9:45.

-3 Gasper WJ, Jamshidi R, Theodore PR: Palliation of thoracic malignancies. Surg Oncol 2007;16:259-265.

-4 Kim JH, Lee HS, Kim MS, Lee JM, Kim SK, Zo JI: Balloon dilatation of the pylorus for delayed gastric emptying after esophagectomy. Eur J Cardiothorac Surg 2008;33:1105-1111.

5 Martin JT, Federico JA, McKelvey AA, Kent MS, Fabian T: Prevention of delayed gastric emptying after esophagectomy: a single center's experience with botulinum toxin. Ann Thorac Surg 2009;87:1708-1713; discussion 1713-1714.

-6 Urschel JD, Blewett CJ, Young JE, Miller JD, Bennett WF: Pyloric drainage (pyloroplasty) or no drainage in gastric reconstruction after esophagectomy: a meta-analysis of randomized controlled trials. Dig Surg 2002;19:160-164.

7 Pennathur A, Chang AC, McGrath KM, et al: Polyflex expandable stents in the treatment of esophageal disease: initial experience. Ann Thorac Surg 2008;85:1968-1972; discussion 1973.

-8 Sutcliffe RP, Forshaw MJ, Tandon R, et al: Anastomotic strictures and delayed gastric emptying after esophagectomy: incidence, risk factors and management. Dis Esophagus 2008;21:712-717.

$\checkmark 9$ Madhusudhan C, Saluja SS, Pal S, et al: Palliative stenting for relief of dysphagia in patients with inoperable esophageal cancer: impact on quality of life. Dis Esophagus 2009;22:331-336.

10 Park JG, Jung GS, Oh KS, Park SJ: Double-layered PTFE-covered nitinol stents: experience in 32 patients with malignant esophageal strictures. Cardiovasc Intervent Radiol 2009, Epub ahead of print.

11 Kiely JM, Dua KS, Graewin SJ, et al: Palliative stenting for late malignant gastric outlet obstruction. J Gastrointest Surg 2007;11:107-113.

12 Nassif T, Prat F, Meduri B, et al: Endoscopic palliation of malignant gastric outlet obstruction using self-expandable metallic stents: results of a multicenter study. Endoscopy 2003;35:483-489.

13 Sreedharan A, Harris K, Crellin A, Forman D, Everett SM: Interventions for dysphagia in oesophageal cancer. Cochrane Database Syst Rev 2009;4:CD005048. 